\title{
Effectiveness of mental therapy for poor medication adherence in depression: A review
}

\author{
Shuyin Xu, Bangshan Liu, Yan Zhang* \\ Mental Health Institute, The Second Xiangya Hospital of Central South University, Changsha, Hunan 410011, China
}

*For correspondence: Email: zhangyan_psychia@126.com; Tel: 0086-13807315182

Sent for review: 14 March 2020

Revised accepted: 24 July 2020

\begin{abstract}
Purpose: To review the effectiveness and underlying mechanism of different types of psychotherapy to improve medication adherence (MA).

Methods: In this review, the status and possible factors influencing medication adherence in patients with depression patients based on information obtained from various literature.

Results: Although the focus of psychologists' analysis of the causes and solutions of mental illness is different, several of these therapies can improve patient compliance with their medications. An effective psychotherapy can change patients' attitudes towards disease and help them reduce the disease recurrence rate.

Conclusion: Psychotherapy has an irreplaceable role in dealing with the major depressive disorder. This review aimed to provide effective instructions for improving medication adherence and reducing disease relapse and recurrence in the future.
\end{abstract}

Keywords: Depression, Medication adherence, Psychotherapy

\begin{abstract}
This is an Open Access article that uses a fund-ing model which does not charge readers or their institutions for access and distributed under the terms of the Creative Commons Attribution License (http://creativecommons.org/licenses/by/4.0) and the Budapest Open Access Initiative (http://www.budapestopenaccessinitiative.org/read), which permit unrestricted use, distribution, and reproduction in any medium, provided the original work is properly credited.

Tropical Journal of Pharmaceutical Research is indexed by Science Citation Index (SciSearch), Scopus, International Pharmaceutical Abstract, Chemical Abstracts, Embase, Index Copernicus, EBSCO, African Index Medicus, JournalSeek, Journal Citation Reports/Science Edition, Directory of Open Access Journals (DOAJ), African Journal Online, Bioline International, Open-J-Gate and Pharmacy Abstracts
\end{abstract}

\section{INTRODUCTION}

Major depressive disorder (MDD) is a common psychiatric disease, and poor medication adherence (MA) is one of the most serious problems in those patients. Optimal treatment often includes a combination of therapy and antidepressant medication. Systematic treatment is recommended for depression, and those MDD should take long-term or even life-long medications to avoid recurrence. Recurrence means depressive symptoms reappearing after two months of being depression-free. Patients who discontinue treatment can cause recurrence and increase treatment difficulty. However, the compliance of medicine taking is still a severe problem for psychopaths. The research shows that the recurrence of discontinued treatment is twice as long as continued treatment [1]. Hence, whether to follow the doctor's advice and treatment scheme is an important factor affecting the recurrence rate. According to a previous investigation, over $50 \%$ MDD patients who stay in treatment exhibit poor MA [2]. The reasons behind the phenomenon include both patient and clinician factors [3].

Factors affecting the treatment of depression include medication efficacy, potential side effects, and illness anxiety disorder associated 
with increased complaints of adverse reactions [4], therapeutic regimen [5], and depression itself [6]. Adherence is related to patient factors ( beliefs in medication and illness, lower stage of patient's condition, medication side effects and illness anxiety), clinical factors (low education of the patient, poor follow-up), social factors (isolation, poverty, no social support, low income, little educational) or medication aspects (budget , side effects) [7]. The patients without adherence were more expected to have relapse or an increased risk of recurrence, hospital visits, hospitalization rates, and increased seriousness of depression and suicidal ideation [8].

Drugs seem to be a very important factor in antidepressant compliance: awareness of the need increases drug dependence because people don't have to worry about need. Belief about medicines causing harm, over-prescribing, experimental adverse effects, and depression severity are negatively correlated with adherence [9]. Twenty two percent of patients taking antidepressants withdrew medication without the suggestion from their doctors [10]. Adverse drug reactions are the most common factor accounting for poor adherence [11]. At least 38 $\%$ of MDD patients have experienced at least one adverse effect caused by antidepressants, and many patients reduce the dose or arbitrarily change drugs due to adverse effects [12].

Besides, it usually takes more than 2 weeks for antidepressants to work; some patients would withdraw when no obvious benefit was seen in the first several weeks. Compared to somatic diseases, the feeling of hopelessness and stigma may be also contributed to the low adherence in depression [13]. It is very common that people with antisocial personality disorder have a sense of stigma, which would reduce patients' compliance and lead to treatment interruption. Therefore, it is of key significance to underline the necessity of adherence to medication and the adverse outcome of nonadherence, in order to achieve satisfying effectiveness, psychiatrists should consider all these passive factors and overcome them.

In general, the treatment of depression is mainly based on medication, supplemented by psychotherapy. Several mainstream psychotherapy such as cognitive behavioral therapy, interpersonal therapy and mindfulness therapy, are as effective as pharmacotherapy for patients with mild or moderate severity of depression. It has been shown that the psychosocial intervention is an effective intervention to improve adherence in depression [14]. However, in terms of improving patient's compliance, there is no consistent statement about which psychotherapy is more effective or the difference in efficacy between them. Therefore, in order to improve patient's treatment compliance and explore their clinical significance, the main psychotherapy methods of depression and the analysis of relevant research data are enumerated.

\section{METHODS}

\section{Cognitive behavioral therapy}

Cognitive behavioral therapy (CBT) is well documented psychosocial treatment in psychiatry. It is the combination of cognitive therapy (CT) and behavior therapy (BT), which is based on the belief that people's behavior is deeply influenced by their automatic negative thoughts. The therapist uses an active socratic questioning style to teach the client how to substitute thoughts that are more rational. Various activation techniques are used to facilitating positive behaviors, including increasing the number of enjoyable activities, relaxation exercises, tracking moods and social skills training. Monitoring mood and impact and doing homework assignment are essential components of CBT. Those techniques can effectively improve patient compliance with drugs. Numerous RCTs and meta-analyses proved that CBT is more effective than controls in reducing the risk of developing a new relapse [15]. Sequential application of CBT following treatment with antidepressants has also shown benefits in converting partial remitters to full remitters, helping to discontinue antidepressants, and preventing relapse after stopping medications [16]. Besides, the use of internet and computer-assisted programs to deliver CBT may be effective intermediations for MDD, as it would make CBT much more manageable to patients [17]. The internet-based CBT is a promising platform to access more people need to be assisted and it can effectively reduce the missing dose and withdrawal rate, and then improve the symptoms of depression [18].

\section{Interpersonal psychotherapy}

Interpersonal psychotherapy (IPT) is a timelimited, focused, evidence-based method for treating emotional disorders. The aim of IPT is to improve the quality of a patient's interpersonal relationships and social functions to help relieve their problems. IPT explores the interpersonal factors related to onset, exacerbation, perpetuation and alleviation of their diseases, enhance their self-respect and social skills, and aid the patients to have more support from the 
society. IPT does more than address shortcomings in interpersonal communication, including, for example, social isolation or participation in unpleasant relationships. It can assist patients to deal with unresolved misery, whether recent or past if grief is related to the death of a loved one. IPT can also help with difficult life transitions such as divorce, retirement or moving to a new city. Likewise, it is recommended to use IPT to handle interpersonal disputes initiated by conflicts of expectations among close friends, colleagues, partners or family members. IPT includes individual, group and telephone-based therapy. Group therapy includes participation of several patients and needs more interaction between different patients.

Patients with the similar symptoms are easy to produce effective resonance and think about their disease objectively. The "group dynamic" effect and interaction between participants of the group is effective for alleviate the symptoms. Madsen et al [19] found that interpersonal relationship exerted significant influence on MA, building therapeutic alliance at the initial several times of therapy is effective in improving MA, especially at the time when the antidepressants has not yet work. However, compared to cognitive therapy (CT), IPP has not been shown to have some enduring effects after acute treatment to reduce relapse and recurrences. Maintenance forms both of CBT and IPP have been developed to prevent loss of therapeutic effect, but these have yet to be systematically evaluated.

\section{Psychodynamic therapy}

Psychoanalytic therapy is one of the most misunderstood methods for mental health patients. The purpose of this therapy is to help patients better understand their subconscious power so that they may play a responsibility in current performances, thoughts and passions. The psychodynamic therapists believe that the traumatic experience in the past would remain in patients' subconscious and lead to negative influence in the future. By studying the influence of experience on patient thinking and behavior patterns, we can help patients understand themselves and improve their introspection.

At the early stage of treatment, we can find patients' pathologic interpersonal relationship by studying their behavior, emotion and experience to remit their inner conflicts and improve their compliance of treatment. A meta-analysis shows that with the brief psychodynamic treatment, patients' symptom and social capability can be improved [20]. Analysis and interpretation of emotional experience and expression is very effective in the early stage of psychological treatment of depression. However, there are very limited data showing the relationship between psychodynamic therapy and MA.

\section{Family therapy}

Marriage and family therapists as well as psychiatry, psychology, social work and psychiatric nursing are the central part of the health profession. Affected by psychoanalysis and psychodynamic, family therapy focuses on the connection between patient psychological problems and family background. This therapy focuses on intervening patients' family and it solves individual's problem by communicating with their family members and studying the relationship among them. Marital conflict is commonly seen in psychiatric patients. Poor family relationship is one of the most common predispositions of psychiatric diseases, and disease can exacerbate family relationship vice versa.

Family therapist focused on the constitute, structure, communication and function of the family, especially those factors related to the onset, perpetuation and alleviation of disease, and applied specific intervention technique based on a systemic perspective. MDD's family therapy usually includes four stages: coping with depression, changing family dynamics, overcoming different challenges for individuals and planning for the future [21]. A longitudinal telephone survey found that the reduction in depression severity and improvement in MA are closely related to higher satisfaction with efforts by clinicians to involve families in care [22]. Much has been reported, including family involvement in evidence-based treatment for severe mental illness [23]. In addition, research shows that mental health consumers report increased satisfaction with mental health services when clinicians include families in consumer care [23], but few studies have specifically targeted family involvement in the treatment of depression.

\section{Mindfulness-based cognitive therapy}

Mindfulness means gaining internal experience, that is, being aware of the moment and making non-evaluative and non-judgmental attempts to think and feel. Mindfulness-based cognitive therapy (MBCT) is an alternative to $\mathrm{CT}$ that incorporates medication and mindfulness techniques to treat long term feelings of unhappiness and depression. Focusing attention on the current moment rather than on guilt of the 
past or about the future can prevent negative thoughts from falling into a state of depression. Studies of MBCT have shown efficacy in preventing episodes in people with recurrent depression [24]. MBCT has also been shown to prevent relapses and recurrences following acute seizures

\section{Problem-solving therapy}

Problem solving therapy (PST) is a short psychosocial treatment for patients who are frustrated and troubled by problem solving skills. The PST model guides patients in identifying problems, effectively solving problems and managing related depressive symptoms. PST centered on building problem-solving scheme, discovering patients' inner positive factors to induce positive change. This therapy is short and economical, dealing with core issues with minimal time and expense; it is more easily to be accepted by patients [25]. The focus-solving solution is different from psychoanalysis, which does not focus on the past but the future of the patient. That is to say, it does not emphasize the negative factors that influence compliance, but emphasizes the positive factors and put them into practice.

PST teaches a structured approach to identifying problems and using pragmatic problem-solving techniques. These include breaking down problems into manageable components, sorting priorities, brainstorming solutions, and listing advantages and disadvantages for potential solution. Several large, pragmatic RCTs have shown superior outcomes with PST compared to treatment as usual for MDD in primary care practices [26]. One advantages of PST is that the health care workers who do not specialize in mental health (such as: nurses, family physicians, care managers) can deliver it and only brief training is required. Therefore, PST can become more widely available than other therapies that need more extensive training and experience.

\section{Motivational interviewing}

Motivation interview (MI) is a coaching method that helps people resolve conflicting emotions and insecurities, thereby finding the internal motivation needed to amend behavior. This is a pragmatic, understanding short-term process, considering how difficult it is to change life. It is effective in alleviating resistance and inspiring the motive to change by reactive listening. Literature has pointed out that even if the patients have sufficient understanding of their disease and medication, they may not follow to the doctor's instructions [27]. For the patients who are having difficulty with MA, MI may be especially suitable. MI is an evidence-centric and patient-centric approach that enhances the inherent motivation to change healthy behaviors. Apply MI technologies such as reflective listening and resistive scrolling is to help patients identify motivations for change and create action schemes.

The combination of $\mathrm{Ml}$ and self-determination theory can provide strategies to enhance autonomy, optimize collaboration and motivation for adherence. Many studies have shown that healthcare providers can apply $\mathrm{Ml}$ as a counseling technique to team up with patients to explore their feelings of ambivalence about change and then guide them in setting goals and plans. It is not just telling patients what went wrong or what should be changed; it is listening to what they think is important and helping them find motivation for change. Lack of clarity and consensus on the content of the treatment is one of the main obstacles; incorporating patients' views on treatment into their joint decision may lead to increased treatment adherence and motivation [28].

MI can be used as an "adherence-focused" psychotherapy. In a study, a smartphone intervention queried the patient about their reasons for nonadherence and then provided tailored motivational feedback to encourage adherence [29]. A cluster RCT use MI on depressed patients to assess their expressions of interest in depression therapy and short-term treatment adherence, showing that $\mathrm{Ml}$ resulted in more frequent change talk, more physical activity and better short-term adherence [30].

\section{Integrated brief psychotherapy}

Based on the "bio-psycho-social" model of modern medicine, integrated brief psychotherapy (IBP) integrates the psychodynamics, brief family therapy, brief cognitive behavioral therapy, brief problem-solving therapy, motivational therapy, interpersonal therapy and mindfulness-based therapy [31]. Because of complex social background and patients' personality, single psychotherapy does not work well in many situations. Some therapists may advocate that they take merely one therapy, but in real practice, they adopt several technologies unconsciously [32]. The IBP combined several psychotherapy techniques together and helps doctors to assess patients and find out the problems to adopt relevant treatment plan. A recent research suggests that flexibly to incorporate a limited amount of cognitive- 
behavioral (CB) strategies early in the psychodynamic treatment of depression can add some benefits to a unique positive correlation between adherence and prognosis [33].

The term "integrated" does not mean simple stack or mixture of different psychotherapies, the essence of integrated psychotherapy is pursuing the optimal effectiveness of psychotherapy without sticking to any specific genre of theory or technique. It advocates the therapist to take the initiative to choose the most suitable therapy for specific patient. "Eclectic psychotherapy" is the use of various techniques from different types of psychotherapy. Some evidences suggest that the more experienced the therapist and the greater the integrity of the therapist to the structure of a particular psychotherapy and the better the outcome. It means that therapists need to understand the theories and methods of different schools of therapy proficiently and construct therapy plan appropriately. Only in this way, the therapist can solve the core problems of the patients efficiently.

The term "brief" is compared to the traditional "long-term" psychotherapy, pointing to solve the patients' problems with the least time. The frequency of therapy in accordance with the clinic guidebook is 12 to 20 times, but some articles mentioned that, with enough training and supervision, there is no obvious difference between long-term therapy (12-20 times) and short-term therapy (6-8 times). For example, the psychodynamic psychotherapy has developed a lot in the past years, the treatment duration is reduced and the maximum number of sessions is specified. Moreover, techniques from other therapeutic orientations are integrated, it turns out that short term psychodynamic psychotherapy meets modern requirements in efficiency, simplicity and transparency [34]. If there are more clinic evidences showing that short-term therapy has the same or even better efficacy, a great deal of medical resources can be saved.

\section{Review findings}

In a large prospective study, the recurrence rate in MDD outpatients was $85 \%$ during a 15-year follow-up term [35]. In addition, a $16 \%$ increased risk of recurrence has been demonstrated after each successive episode [36]. Given the high psychological, social and economic burden associated with MDD, prevention of relapse / relapse is very critical. Maintenance therapy with antidepressant drugs (mADM) is the most common strategy for preventing relapse / relapse. The relapsed MDD should continue treatment with mADM for at least two years after remission. A meta-analysis indicated that mADM treatment significantly decreases relapse/recurrence rates from 41 to $18 \%$ compared to control based on 31 RCT with follow-up periods from 6-36 months [37]. However, although mADM has established effectiveness as a preventive strategy, it has some disadvantages. First, many patients are hesitant to keep it longer [38] and adherence is ordinarily low [39]. Second, many cases experience side effects [40]. In addition, many patients prefer psychological over medication.

A history of mental illness, age, and gender do not seem to affect adherence, but a low income, over-prescription, and stigma over treatment of mental illness and psychosis are all connected to treatment compliance. Race and ethnicity is a strong robust predictor of early antidepressant adherence, while minorities have lower adherence in American society [41]. Women seem to follow treatment indications better [42]. Jirón et al pointed out that when gender factors are combined with low income, women's adherence was poor [43].

To concentrate the necessity for psychological interventions targeting relapse prevention, Segal et al developed MBCT [44]. The purpose of MBCT is not to eliminate the symptoms of depression, but to connect it with depression in a different way, that is in a more acceptable and gentle manner. The basic principles of the MBCT program are based on an empirical-supported theoretical framework, implying that patients with recurrent depression are more likely to come into being depression as their cognitive response capacity improves. Cognitive responses are negative ways of thinking and acting that reactivate when stressed or depressed. It is indicated that these (automatic) negative reactions, in turn, will lead to a further decrease in mood and eventually become a depressive relapse / relapse [44]. Cognitive reactions are closely related to introspection. Introspection refers to repeatedly thinking about a person's symptoms of depression. Rumination is considered an imperative cognitive vulnerability factor for the onset and recurrence of depression [45]. MBCT aims to identify cognitive and behavioral responses to depressed mood or other stressful situations, to monitor, accept and treat these responses. Self-compassion (SC) appears to be a useful factor in preventing depression. SC can be designated as (a) a combination of SC-kindness and understanding of yourself in the case of pain or failure; (b) ordinary humans-perceiving their experiences as part of a wider human event; and (c) 
mindfulness-maintaining painful thoughts and feelings in a balanced consciousness. There is evidence that both self-compassion and mindfulness skills can promote MBCT's effect on relapse / relapse [46].

Data from 3 RCTs showed that MBCT significantly decreases the risk of relapse / relapse over a period of 14 months compared to conventional treatment (TAU) [47]. MBCT can reduce subthreshold depression symptoms of MDD patients and current MDD patients, which is an important risk factor for relapse / relapse. A recent meta-analysis [48] showed that compared with TAU or placebo, the overall risk of $\mathrm{MBCT}$ recurrence / recurrence was 0.66 (relative risk reduction $34 \%$ ), indicating that $\mathrm{MBCT}$ is indeed an effective preventive measure for relapse in MDD patients.

A history of prior episodes may also be strict to MBCT and CBT: a prescriptive effect was discovered in the first two MBCT RCTs, both of which were performed in small samples by the same research team, and they have not been replicated since patients with fewer than three episodes are currently excluded from those RCTs. Similarly, one study showed in a post hoc analysis that the persistent effect of CBT (relative to TAU) was only apparent in patients with five or more episodes, but this finding has not been confirmed [49]. A review of the ADM interruption study found no prescription consequences [50]. Although the history of previous episodes appears to be prognostic and may be prescriptive, the confidence of accepting such an effect at the scene seems to be somewhat exaggerated.

\section{Implications and recommendations}

Evidence-based psychotherapy is an effective first-line treatment for mild to moderate levels of depression. For more severe, chronic or comorbid depression symptoms, combined psychotherapy and pharmacotherapy is indicated. The advantages of combination therapy are that it can improve symptom at the early stage, increasing patients' compliance, and promote the recovery of social function recovery. Low compliance would not only do harm to the patients, but also cause more pressure to the society.

\section{CONCLUDING REMARKS}

Referring to the relevant articles, although the focus of analysis on causes and solutions to mental diseases varies from psychologists, all of these therapies could improve the patients' compliance. An effective psychotherapy can change patients' attitudes towards disease. When they encounter the same inner bewilderment, they can solve it themselves, which indirectly reduces the recurrence rate. It should be noted that adherence-focused psychotherapy or counseling by telemental health delivers unique prospects to improve access to quality mental health services. This includes enabling telemedicine services, magnifying the scope of services for qualified mental health personnel, improving clinical management and training, promoting cost and time efficiency, and augmenting clinicians' daily workflow and clinical procedures. Psychotherapy is irreplaceable in MDD treatment.

\section{DECLARATIONS}

\section{Acknowledgement}

None provided

\section{Conflict of interest}

No conflict of interest is associated with this work.

\section{Contribution of authors}

We declare that this work was done by the authors named in this article and all liabilities pertaining to claims relating to the content of this article will be borne by the authors. Yan Zhang conceived and designed the study, Shuyin $\mathrm{Xu}$ collected and analysed the data, and Bangshan Liu wrote the manuscript and made critical rewriting after the co-authors' review. All authors read and approved the manuscript for publication.

\section{Open Access}

This is an Open Access article that uses a funding model which does not charge readers or their institutions for access and distributed under the terms of the Creative Commons Attribution License (http://creativecommons.org/licenses/by/ 4.0) and the Budapest Open Access Initiative (http://www.budapestopenaccessinitiative.org/rea d), which permit unrestricted use, distribution, and reproduction in any medium, provided the original work is properly credited.

\section{REFERENCES}

1. Wunderink L, Nieboer RM, Wiersma D, Sytema S, Nienhuis FJ. Recovery in remitted first-episode psychosis at 7 years of follow-up of an early dose

Trop J Pharm Res, August 2020; 19(8): 1790 
reduction/discontinuation or maintenance treatment strategy: long-term follow-up of a 2-year randomized clinical trial. JAMA Psychiatry. 2013; 70(9): 913-920.

2. Rush AJ, Thase ME. Improving Depression Outcome by Patient-Centered Medical Management. Am J Psychiatry. 2018; 175(12): 1187-1198.

3. Holvast F, Oude Voshaar RC, Wouters H, Hek K, Schellevis F, Burger $H$, Verhaak PFM. Non-adherence to antidepressants among older patients with depression: a longitudinal cohort study in primary care. Fam Pract. 2019; 36(1): 12-20.

4. Keeley R, Smith M, Miller J. Somatoform symptoms and treatment nonadherence in depressed family medicine outpatients. Arch Fam Med. 2000; 9(1): 46-54.

5. Hansen DG, Vach W, Rosholm JU, Søndergaard J, Gram $L F, \quad K r a g s t r u p \quad J . \quad$ Early discontinuation of antidepressants in general practice: association with patient and prescriber characteristics. Fam Pract. 2004; 21(6): 623-629.

6. Unützer J, Katon $W$, Callahan $C M$, Williams JW Jr, Hunkeler E, Harpole L, Hoffing M, Della Penna RD, Noel $P H$, Lin EH, Tang $L$, et al. Depression treatment in a sample of 1,801 depressed older adults in primary care. J Am Geriatr Soc. 2003; 51(4): 505-514.

7. Martín MJ, García-toro M, Campoamor F, Pareja A, Aguirre I, Salvá J, Roca M. Uso de los tratamientos antidepresivos. Actas Esp Psiquiatr. 2009; 37(5): 276281.

8. Ho SC, Chong HY, Chaiyakunapruk N, Tangiisuran B, Jacob SA. Clinical and economic impact of nonadherence to antidepressants in major depressive disorder: A systematic review. J Affect Disord. 2016; 193: $1-10$

9. Fawzi W, Abdel Mohsen MY, Hashem AH, Moussa S, Coker E, Wilson KC. Beliefs about medications predict adherence to antidepressants in older adults. Int Psychogeriatr. 2012; 24(1): 159-169.

10. Samples H, Mojtabai R. Antidepressant selfdiscontinuation: results from the collaborative psychiatric epidemiology surveys. Psychiatr Serv. 2015; 66(5): 455462.

11. Kinon BJ, Liu-Seifert $H$, Adams $D H$, Citrome $L$. Differential rates of treatment discontinuation in clinical trials as a measure of treatment effectiveness for olanzapine and comparator atypical antipsychotics for schizophrenia. J Clin Psychopharmacol. 2006; 26(6): 632-637.

12. Cascade E, Kalali AH, Kennedy SH. Real-World Data on SSRI Antidepressant Side Effects. Psychiatry (Edgmont). 2009; 6(2): 16-18.

13. Sedlácková Z, Kamarádová $D$, Prásko J, Látalová $K$, Ocisková $M$, Ocisková $M$, Cinculová A, Kubínek $R$, Mainerová $B$, Tichácková $A$, et al. Treatment adherence and self-stigma in patients with depressive disorder in remission - A cross-sectional study. Neuro Endocrinol Lett. 2015; 36(2): 171-177.

14. Sirey JA, Banerjee $S$, Marino $P$, Bruce ML, Halkett $A$, Turnwald M, Chiang C, Liles B, Artis A, Blow F, et al.
Adherence to Depression Treatment in Primary Care: A Randomized Clinical Trial. JAMA Psychiatry. 2017; 74(11): 1129-1135.

15. Hofmann SG, Asnaani A, Vonk IJ, Sawyer AT, Fang A. The Efficacy of Cognitive Behavioral Therapy: A Review of Meta-analyses. Cognit Ther Res. 2012; 36(5): 427440.

16. Kazantzis N, Brownfield NR, Mosely L, Usatoff AS, Flighty AJ. Homework in Cognitive Behavioral Therapy: A Systematic Review of Adherence Assessment in Anxiety and Depression (2011-2016). Psychiatr Clin North Am. 2017; 40(4): 625-639.

17. Rost T, Stein J, Löbner M, Kersting A, Luck-Sikorski C, Riedel-Heller SG. User Acceptance of Computerized Cognitive Behavioral Therapy for Depression: Systematic Review. J Med Internet Res. 2017; 19(9): e309.

18. Ruwaard J, Lange A, Schrieken B, Dolan CV, Emmelkamp $P$. The effectiveness of online cognitive behavioral treatment in routine clinical practice. PLOS One. 2012; 7(7): e40089.

19. Madsen JW, McQuaid JR, Craighead WE. Working with reactant patients: are we prescribing nonadherence? Depress Anxiety. 2009; 26(2):129-134.

20. Leichsenring F, Rabung S, Leibing $E$. The efficacy of short-term psychodynamic psychotherapy in specific psychiatric disorders: a meta-analysis. Arch Gen Psychiatry. 2004; 61(12): 1208-1216.

21. Priestley J, McPherson S. Experiences of adults providing care to a partner or relative with depression: $A$ meta-ethnographic synthesis. J Affect Disord. 2016; 192: 41-49.

22. Bolkan CR, Bonner LM, Campbell DG, et al. Family involvement, medication adherence, and depression outcomes among patients in veterans affairs primary care. Psychiatr Serv. 2013; 64(5): 472-478.

23. Prince JD. Family involvement and satisfaction with community mental health care of individuals with schizophrenia. Community Ment Health J. 2005; 41(4): 419-430.

24. Kuyken $W$, Hayes $R$, Barrett B, Byng $R$, Dalgleish $T$, Kessler D, Lewis G, Watkins E, Brejcha C, Cardy J, et al. The effectiveness and cost-effectiveness of mindfulness-based cognitive therapy compared with maintenance antidepressant treatment in the prevention of depressive relapse/recurrence: results of a randomised controlled trial (the PREVENT study). Health Technol Assess. 2015; 19(73): 1-124.

25. Liu X, Zhang YP, Franklin C, Qu Y, Chen H, Kim JS. The practice of solution-focused brief therapy in mainland China. Health Soc Work. 2015; 40(2): 84-90.

26. Bell AC, D'Zurilla TJ. Problem-solving therapy for depression: a meta-analysis. Clin Psychol Rev. 2009; 29(4): 348-353

27. Tay SE. Compliance therapy: an intervention to improve inpatients' attitudes toward treatment. J Psychosoc Nurs Ment Health Serv. 2007; 45(6): 29-37.

Trop J Pharm Res, August 2020; 19(8): 1791 
28. van Grieken RA, Beune EJ, Kirkenier AC, Koeter MW, van Zwieten MC, Schene AH. Patients' perspectives on how treatment can impede their recovery from depression. J Affect Disord. 2014; 167:153-159.

29. Kreyenbuhl J, Record EJ, Himelhoch S, et al. Development and Feasibility Testing of a Smartphone Intervention to Improve Adherence to Antipsychotic Medications. Clin Schizophr Relat Psychoses. 2019; 12(4): 152-167.

30. Keeley RD, Burke BL, Brody D, Dimidjian S, Engel M, Emsermann $C$, deGruy $F$, Thomas M, Moralez $E$, Koester $S$, et al. Training to use motivational interviewing techniques for depression: a cluster randomized trial. J Am Board Fam Med. 2014; 27(5): 621-636.

31. Winston A, Winston B. Toward an integrated brief psychotherapy. J Psychiatr Pract. 2001; 7(6):377-390.

32. Katz-Bearnot S. Combined psychotherapies: searching for an order of operations in a disordered world. J Am Acad Psychoanal Dyn Psychiatry. 2009; 37(2): 299-313.

33. Katz M, Hilsenroth MJ, Gold JR, Moore M, Pitman SR, Levy SR, Owen J. Adherence, flexibility, and outcome in psychodynamic treatment of depression. J Couns Psychol. 2019; 66(1): 94-103.

34. Derksen JJ. Short-term psychodynamic psychotherapy. Tijdschr Psychiatr. 2006; 48(10): 777-786.

35. Mueller TI, Leon AC, Keller MB, Solomon DA, Endicott J, Coryell W, Warshaw M, Maser JD. Recurrence after recovery from major depressive disorder during 15 years of observational follow-up. Am J Psychiatry. 1999; 156(7): 1000-1006.

36. Solomon DA, Keller MB, Leon AC, Mueller TI, Lavori PW, Shea MT, Coryell W, Warshaw M, Turvey C, Maser JD, et al. Multiple recurrences of major depressive disorder. Am J Psychiatry. 2000; 157(2): 229-233.

37. Geddes JR, Carney SM, Davies C, Furukawa TA, Kupfer $D J$, Frank E, Goodwin GM. Relapse prevention with antidepressant drug treatment in depressive disorders: a systematic review. Lancet. 2003; 361(9358): 653-661.

38. Bockting CL, ten Doesschate MC, Spijker J, Spinhoven $P$, Koeter MW, Schene AH; DELTA study group. Continuation and maintenance use of antidepressants in recurrent depression. Psychother Psychosom. 2008; 77(1): 17-26.

39. ten Doesschate MC, Bockting CL, Schene AH. Adherence to continuation and maintenance antidepressant use in recurrent depression. J Affect Disord. 2009; 115(1-2): 167-170.
40. Kelly K, Posternak M, Alpert JE. Toward achieving optimal response: understanding and managing antidepressant side effects. Dialogues Clin Neurosci. 2008; 10(4): 409-418.

41. Rossom RC, Shortreed S, Coleman KJ, Beck A, Waitzfelder BE, Stewart C, Ahmedani BK, Zeber JE, Simon GE. Antidepressant Adherence Across Diverse Populations And Healthcare Settings. Depress Anxiety. 2016; 33(8): 765-774.

42. Oller-Canet S, Lacasta-Tintorer D, Castro Jl, GarcíaLecina $R$, Flamarich-Zampalo $D$, Font-Canal $T$, Fernández-San Martín MI, Martín-López LM. Toman los pacientes deprimidos el tratamiento prescrito? Estudio descriptivo sobre el cumplimiento del tratamiento antidepresivo. Actas Esp Psiquiatr. 2011; 39(5): 288293.

43. Jirón M, Escobar L, Arriagada L, Orellan S, Castro A. Factores Asociados al Incumplimiento de los Tratamientos con Antidepresivos en Santiago, Chile. Value Health. 2011; 14 (5): 115-118.

44. Segal ZV, Williams JMG, Teasdale JD. Mindfulnessbased cognitive therapy for depression: A new approach to preventing relapse. Guilford Press. 2002.

45. Nolen-Hoeksema S. The role of rumination in depressive disorders and mixed anxiety/depressive symptoms. J Abnorm Psychol. 2000; (109): 504-511.

46. Kuyken W, Watkins E, Holden E, White K, Taylor RS, Byford S, Evans A, Radford S, Teasdale JD, Dalgleish $T$. How does mindfulness-based cognitive therapy work? Behav Res Ther. 2010; 48(11): 1105-1112.

47. Ma SH, Teasdale JD. Mindfulness-based cognitive therapy for depression: replication and exploration of differential relapse prevention effects. J Consult Clin Psychol. 2004; 72(1): 31-40.

48. Piet J, Hougaard E. The effect of mindfulness-based cognitive therapy for prevention of relapse in recurrent major depressive disorder: a systematic review and meta-analysis. Clin Psychol Rev. 2011; 31(6): 10321040.

49. Bockting CL, Schene AH, Spinhoven P, Koeter MW, Wouters LF, Huyser J, Kamphuis JH. Preventing relapse/recurrence in recurrent depression with cognitive therapy: a randomized controlled trial. J Consult Clin Psychol. 2005; 73(4): 647-657.

50. Berwian IM, Walter $H$, Seifritz E, Huys QJ. Predicting relapse after antidepressant withdrawal - a systematic review. Psychol Med. 2017; 47(3): 426-437. 